\title{
Jab1 is a target of EGFR signaling in ER $\alpha$-negative breast cancer
} Jiaxu Wang ${ }^{1}$, Rebecca O Barnes ${ }^{1}$, Nathan R West ${ }^{1,2}$, Melanie Olson ${ }^{1}$, Jenny E Chu ${ }^{1,2}$ and Peter H Watson ${ }^{1,3,4}$

\author{
1Deeley Research Center, BC Cancer Agency, Vancouver Island Center, 2410 Lee Avenue, Victoria, BC, V8R 6V5, Canada \\ 2University of Victoria, PO Box 1700 STN CSC, Victoria, BC, V8W 2Y2, Canada \\ ${ }^{3}$ Molecular Oncology and Breast Cancer Program, BC Cancer Agency, 600 West 10th Avenue, Vancouver, BC, V5Z 4E6, Canada \\ ${ }^{4}$ Department of Pathology, BC Cancer Agency, 600 West 10th Avenue, Vancouver, BC, V5Z 4E6, Canada
}

Corresponding author: Peter H Watson, pwatson@bccancer.bc.ca

Received: 10 Dec 2007 Revisions requested: 4 Feb 2008 Revisions received: 27 Mar 2008 Accepted: 6 Jun 2008 Published: 6 Jun 2008

Breast Cancer Research 2008, 10:R51 (doi:10.1186/bcr2105)

This article is online at: http://breast-cancer-research.com/content/10/3/R51

(c) 2008 Wang et al.; licensee BioMed Central Ltd.

This is an open access article distributed under the terms of the Creative Commons Attribution License (http://creativecommons.org/licenses/by/2.0), which permits unrestricted use, distribution, and reproduction in any medium, provided the original work is properly cited.

\begin{abstract}
Introduction c-Jun activation domain-binding protein-1 (Jab1) is a multifunctional signaling protein that previously has been shown to be a master regulator of a poor prognostic gene signature in invasive breast cancer and to mediate the action of S100A7. Since epidermal growth factor receptor (EGFR), like $\mathrm{S} 100 \mathrm{~A} 7$, is often expressed in estrogen receptor-alphanegative $(E R \alpha)$ breast cancer, we set out to investigate the role of Jab1 in mediating EGFR signaling, another facet of the ER $\alpha$ phenotype.
\end{abstract}

Methods MDA-MB-231 and MDA-MB-468 ER $\alpha / \mathrm{EGFR}^{+}$cell lines were assessed for localization of Jab1 and levels of downstream genes by immunofluorescence and nuclear protein extract assay following treatment with epidermal growth factor (EGF) and extracellular signal-regulated kinase (ERK) pathway inhibitor. A cohort of 424 human breast tumors was also assessed by immunohistochemistry.
Results EGF treatment of cell lines resulted in increased Jab1 nuclear expression. This effect was inhibited by the ERK pathway inhibitor, PD98059. EGF treatment was also associated with colocalization of pERK (phosphorylated ERK) and Jab1 as well as regulation of the Jab1 downstream target gene, p27. When Jab1 activity was knocked down, p27 levels were restored to pre-EGF treatment level. Analysis of EGFR and Jab1 expression in a cohort of invasive breast tumors by tissue microarray and immunohistochemistry confirmed a relationship between EGFR and increased nuclear Jab1 within the ER $\alpha$ subset ( $\mathrm{n}=154, P=0.019$ ). The same association was also confirmed for S100A7 and Jab1 $(P=0.036)$, and high Jab1 nuclear expression was most frequent in tumors that were positive for both EGFR and S100A7 $(P=0.004)$.

Conclusion Jab1 is a target of EGFR signaling in ER $\alpha^{-}$cell lines and breast tumors and therefore may be a common central factor and potential therapeutic target for important cell signaling pathways in ER $\alpha$ - breast cancer.

\section{Introduction}

Recent therapeutic advances have improved survival for many patients with breast cancer. These advances have been most impressive for targeted therapies, such as those targeting the estrogen receptor (ER) and the human epidermal growth factor receptor (EGFR) 2 (Her2). These advances have specifically benefited the subsets of patients with tumors that exhibit $\mathrm{ER} \alpha^{+}$or $\mathrm{Her}^{+}$phenotypes, respectively. Other subsets of tumors such as the so-called 'triple-negative' breast tumors,
$\mathrm{ER} \alpha$ /progesterone receptor-negative (PR-)/Her2;, remain difficult to treat. The ER $\alpha$ - phenotype, which includes the triplenegative phenotype, has dominated clinical and biological consideration of breast cancer for many years and has been reproducibly shown in microarray studies to be distinct from $\mathrm{ER} \alpha^{+}$breast cancer $[1,2]$. Identification of key signaling molecules and pathways relevant to ER $\alpha$ - breast cancer is therefore an important step toward the goal of improving breast cancer therapy [3-5].

$\overline{\mathrm{AP}}-1$ = activation protein-1; DCIS = ductal carcinoma in situ; EDTA = ethylene diamine tetraacetic acid; EGF = epidermal growth factor; EGFR = epidermal growth factor receptor; EGTA = ethylene glycol tetraacetic acid; ER = estrogen receptor; ERK = extracellular signal-regulated kinase; $\mathrm{GAPDH}=$ glyceraldehyde 3-phosphate dehydrogenase; HEPES = 4-(2-hydroxyethyl)-1-piperazineethanesulfonic acid; Her2 = epidermal growth factor receptor 2; IHC = immunohistochemistry; Jab1 = c-Jun activation domain-binding protein-1; JNK = c-jun $\mathrm{N}$-terminal kinase; LBA = ligand-binding assay; MAP = mitogen-activated protein; NF- $\mathrm{B}=$ nuclear factor-kappa $\mathrm{B} ; \mathrm{PBS}=$ phosphate-buffered saline; PBST = phosphate-buffered saline + $0.05 \%$ Tween-20; pERK = phosphorylated extracellular signal-regulated kinase; PR = progesterone receptor; siRNA = short interfering RNA; TMA $=$ tissue microarray. 
We and others have previously identified genes that are highly associated with the ER $\alpha$ phenotype, including EGFR and S100A7 [6-11]. Epidermal growth factors (EGFs) are important in the biology of both normal and malignant breast tissue, exerting their effects through their tyrosine kinase growth factor receptors. EGFR expression is strongly associated with the ER $\alpha$ - phenotype [12-14] such that there is a strong inverse relationship between EGFR and the steroid receptor, ER $\alpha$ $[11,15]$. S100A7 (psoriasin) is a small calcium-binding protein belonging to the $S 100$ gene family $[16,17]$. It is highly expressed in some ductal carcinoma in situ (DCIS) [18-20] and invasive breast [18] carcinomas. Within both of these stages, S100A7 expression is strongly related to the ER $\alpha$ phenotype $[6,8]$.

c-Jun activation domain-binding protein-1 (Jab1) is a multifunctional signaling protein and is a target of S100A7 that can mediate many of its biological effects, including induction of nuclear factor-kappa B (NF-kB) and promotion of cell survival $[21,22]$. Additional evidence that Jab1 is a key gene in breast cancer progression comes from the recent finding that it is a downstream target for Her2 [23]. Furthermore, Jab1 has been found to interact with c-myc to act as a master regulator of the 'wound response' gene signature in breast cells [24,25]. The wound response signature represents a conserved cluster of gene responses to changes in serum, exclusive of known proliferation response genes. It can be generated in epithelial and fibroblast cells and is associated with poor outcome in invasive breast cancer. Jab1 also interacts with many components of known cell signaling pathways in the context of both phosphorylation and proteasomal activities, typically resulting in translocation of Jab1 to the nucleus and modification of activity in downstream pathways. These interactions result in increased activation protein-1 (AP-1) [26] and NF- $\mathrm{KB}$ [22] activity and degradation of the cell cycle inhibitor p27 (Kip1) [27] and the transforming growth factor- $\beta$ signaling component Smad4 [28].

Taken together, these findings implicate Jab1 as an important factor in several signaling pathways in breast cancer. Since the S100A7 gene is strongly associated with the ER $\alpha$ - phenotype and our studies have implicated Jab1 as a mediator of S100A7 action $[7,22]$, we set out to examine the possibility that Jab1 may be an important component of the mechanism of action of other key ER $\alpha$-associated genes, focusing here specifically on EGFR.

\section{Materials and methods Cell lines, antibodies, and reagents}

Human breast carcinoma cell lines MDA-MB-468 and MDAMB-231 (both ER $\alpha$ - and EGFR ${ }^{+}$and derived from invasive breast carcinomas) were cultured in Dulbecco's modified Eagle's medium supplemented with $10 \%$ fetal bovine serum under standard conditions as previously described [8]. The antibodies used for immunoblotting and immunoprecipitation were Jab1 $(1: 3,000)$ (Sigma-Aldrich, Oakville, ON, Canada); p27 (1:200) (BD Biosciences, Mississauga, ON, Canada); Lamin A/C (1:1,000), pEGFR (phosphorylated EGFR) $(1: 1,000)$, extracellular signal-regulated kinase (ERK) $(1: 1,000)$, phosphorylated ERK (pERK) $(1: 1,000)$, AKT $(1: 2,000)$, and pAKT $(1: 1,000)$ (Cell Signaling Technology, Inc., Danvers, MA, USA); EGFR $(1: 1,000)$ (VWR International, Mississauga, ON, Canada); and glyceraldehyde 3-phosphate dehydrogenase (GAPDH) (1:4,000; Advanced ImmunoChemical Inc., Long Beach, CA, USA). The antibody to S100A7 was a rabbit polyclonal generated and described previously $[6,21]$. Goat anti-mouse and goat anti-rabbit lgG secondary antibodies were purchased from Santa Cruz Biotechnology, Inc. (Santa Cruz, CA, USA). All EGF treatments were for 4 hours and, with the exception of the EGF dose experiments, were 50 $\mathrm{ng} / \mathrm{mL}$ (Millipore Corporation, Billerica, MA, USA). Treatments with ERK inhibitor PD98059 were at $20 \mu \mathrm{M}$ for 4 hours (Cell Signaling Technology, Inc.).

\section{Immunofluorescence, nuclear extraction, and immunoblotting}

Following treatment with selected reagent (EGF or PD98059), cells were fixed with $3.7 \%$ formaldehyde, permeabilized with $0.1 \%$ Triton X-100, and blocked with $0.2 \%$ bovine serum albumin. Cells then were stained for Jab1 (1:50) using the primary antibodies described above and Alexa Fluor 488conjugated goat anti-rabbit IgG secondary antibody (1:100) (Invitrogen Corporation, Carlsbad, CA, USA). For doubleimmunostaining of Jab1 and pERK or p27, cells first were stained for Jab1 as described above and then were stained for pERK $(1: 100)$ or p27 $(1: 100)$ using the primary antibodies described above and Alexa Fluor 594-conjugated chicken anti-mouse IgG secondary antibody (1:100) (Invitrogen Corporation). Immunofluorescence images were captured using a Leica DM 6000B immunofluorescence microscope (Leica, Wetzlar, Germany), and image analysis was performed using OpenLab 4.0.4 software (Improvision Ltd., Coventry, UK).

Nuclear extracts were prepared by rinsing culture dishes with phosphate-buffered saline (PBS) and then resuspending cells in a nuclear extracting lysis buffer (10 mM HEPES [4-(2hydroxyethyl)-1-piperazineethanesulfonic acid] [pH 7.9], 10 $\mathrm{mM} \mathrm{KCl}, 0.1 \mathrm{mM}$ EDTA [ethylene diamine tetraacetic acid], and 0.1 mM EGTA [ethylene glycol tetraacetic acid]) and incubating for 20 minutes on ice. Cells were further fractionated by adding $25 \mu \mathrm{L}$ of Nonidet P-40 (10\%), vortexing for 10 seconds, and centrifuging at $15,000 \mathrm{~g}$ for 10 minutes at $4^{\circ} \mathrm{C}$. The pellet (nuclei) was then resuspended in $50 \mathrm{mM}$ HEPES $(\mathrm{pH}$ 7.3), $150 \mathrm{mM} \mathrm{NaCl}, 2.5 \mathrm{mM}$ EGTA, $10 \%$ glycerol, $0.1 \%$ Tween-20, $1 \mathrm{mM} \mathrm{NaF}, 1 \mathrm{mM}$ DTT (dithiothreitol), $0.1 \mathrm{mM}$ $\mathrm{Na}_{3} \mathrm{VO}_{3}$, and one tablet of EDTA-free protease inhibitor (Roche Diagnostics, Basel, Switzerland) per $10 \mathrm{~mL}$, incubated 20 minutes on ice, and then boiled prior to loading. 
Protein samples were separated by SDS-PAGE ( $4 \%$ to $12 \%$ acrylamide) and transferred to $0.2 \mu \mathrm{m}$ nitrocellulose (Bio-Rad Laboratories, Inc., Hercules, CA, USA). After blocking in 5\% skim milk powder in PBST (PBS + 0.05\% Tween-20) for 30 minutes, blots were rinsed in PBST and then incubated with the primary antibody overnight in PBST at $4^{\circ} \mathrm{C}$. Blots were washed in PBST for 10 minutes, three times, and then were incubated with the appropriate secondary antibody for 1 hour, followed by washing in PBST for 10 minutes, three times. Blots were developed by chemiluminescence (enhanced chemiluminescence; made in house) and were exposed to $X$ OMAT Kodak film (Eastman Kodak Company, Rochester, NY, USA). For all assays, at least three separate experiments were performed.

\section{Knockdown of Jab1}

Jab1 expression was inhibited by transfecting cells with a pool of four different Jab1-specific short interfering RNA (siRNA) duplexes (Dharmacon, Inc., Chicago, IL, USA). Scrambled siRNA was used as a non-targeting control (Dharmacon, Inc.). siRNA transfection was carried out using DharmaFECT 1 transfection reagent/vehicle (Dharmacon, Inc.) according to manufacturer recommendations. siRNA was transfected at a concentration of $100 \mathrm{nM}$, after which cells were cultured for 48 hours prior to lysis and protein harvest. Densitometry of Western blots was conducted using Adobe Photoshop (Adobe Systems Incorporated, San Jose, CA, USA). Densitometry results for $\mathrm{p} 27$ were normalized to GAPDH within each treatment. Statistical analysis of p27 densitometry was performed with JMP software (version 7.0) (SAS Institute Inc., Cary, NC, USA) using $t$ tests.

\section{Tissue microarray breast cancer cohort}

After the institutional research ethics board gave ethical approval, a tissue microarray (TMA) was obtained from the Manitoba Breast Tumor Bank (Winnipeg, MB, Canada) to investigate the relationship between Jab1 and EGFR and S100A7 in breast tumors in vivo. The TMA was constructed from duplicate $0.6-\mathrm{mm}$ tissue cores that were removed from the central portion of a representative paraffin block from each tumor and arrayed within one of seven paraffin blocks, using a tissue arrayer (Beecher Instruments, Inc., Sun Prairie, WI, USA). The TMA included interpretable cores from 424 invasive breast carcinomas. Case selection was designed to mirror the distribution of major prognostic clinical-pathological features (size, grade, and lymph node and ER status) that the entire tumor bank collection accrued over the period 1992 to 2002 and was also based on the following criteria: (a) a minimum patient follow-up of 60 months and tumors that had (b) an invasive component of greater than $20 \%$ of the tissue section and (c) less than or equal to $10 \%$ of the normal epithelial content. ER- status was defined by ligand-binding assay (LBA) criteria of less than $3 \mathrm{fmol} / \mathrm{mg}$ protein. The criteria for interpretation of the variables were as follows: (a) $\mathrm{PR}^{+}$status was defined as greater than or equal to $15 \mathrm{fmol} / \mathrm{mg}$ protein by LBA, (b) tumor grading was according to the Nottingham system, and (c) tumor size was classified as either small $(\leq 20 \mathrm{~mm})$ or large $(>20 \mathrm{~mm})$. Patients received a range of treatments, including local radiotherapy $(n=163)$ and systemic hormonal and/or chemotherapy $(n=375)$. Patient outcome was defined as the time from initial surgery to the date of death attributable to breast cancer only.

\section{Immunohistochemistry and statistical analysis}

Immunohistochemistry (IHC) staining for Jab1, EGFR, and S100A7 was performed using an automated tissue immunostainer (Ventana Medical Systems, Inc., Tucson, AZ, USA) and using bulk reagents supplied by the manufacturer (IHC protocol previously described $[6,21])$. Primary antibody incubation for Jab1 and S100A7 was 32 minutes. Tumor cell staining was scored for each protein in semi-serial sections by a single observer (PHW) but in independent sessions for each protein to ensure blinded independent scoring. For Jab1 and S100A7, only nuclear expression was scored as cytoplasmic signals were generally weak and difficult to quantify. IHC staining was scored using a semi-quantitative $\mathrm{IHC}$ score (IHC score $=$ [percentage of positive neoplastic epithelial cells] $\times$ [staining intensity ranked from 0 to 3]) that ranged from 0 to 300. In univariate analysis, cut-points for Jab1 and S100A7 were those used in previous studies $[6,29]$ to distinguish low from high expression (Jab1 IHC scores of greater than 50 , corresponding to nuclear expression in greater than $50 \%$ of tumor cells, and S100A7 IHC scores of greater than 0) or EGFR IHC scores of greater than 100 , corresponding to $2+$ or $3+$ intensity as used for the clinical assessment of Her2 [30]. Statistical analysis was performed with JMP software (version 7.0) (SAS Institute Inc.) and GraphPad Prism (version 4.2) (GraphPad Software, Inc., San Diego, CA, USA) using Spearman correlation, chi-square, Mann-Whitney $t$ test, or log-rank test as appropriate.

\section{Results}

\section{Treatment with EGF influences localization of Jab1}

Jab1 has been shown previously to exist in both the nucleus and cytoplasm of different cell types. However, it has been shown that interactions between Jab1 and many of its downstream targets are associated with translocation of Jab1 to the nucleus. These include interaction with AP-1 [31], NF-KB [32], and p27 [32]. To determine whether Jab1 translocation is affected by EGFR signaling, we first used immunofluorescence microscopy to look for changes in cellular localization of Jab1 following treatment with EGF. We observed that EGF treatment was followed by increased translocation of Jab1 to the nucleus in both MDA-MB-231 and MDA-MB-468 breast cancer cell lines (Figure 1b). This effect is particularly evident in the merged images. Quantitative analysis of Jab1 nuclear expression confirmed that Jab1 levels were approximately twofold higher following EGF treatment compared with untreated cells (Figure 1c). This difference was statistically significant in both cell lines tested $(P<0.01)$. These results were confirmed 
Figure 1

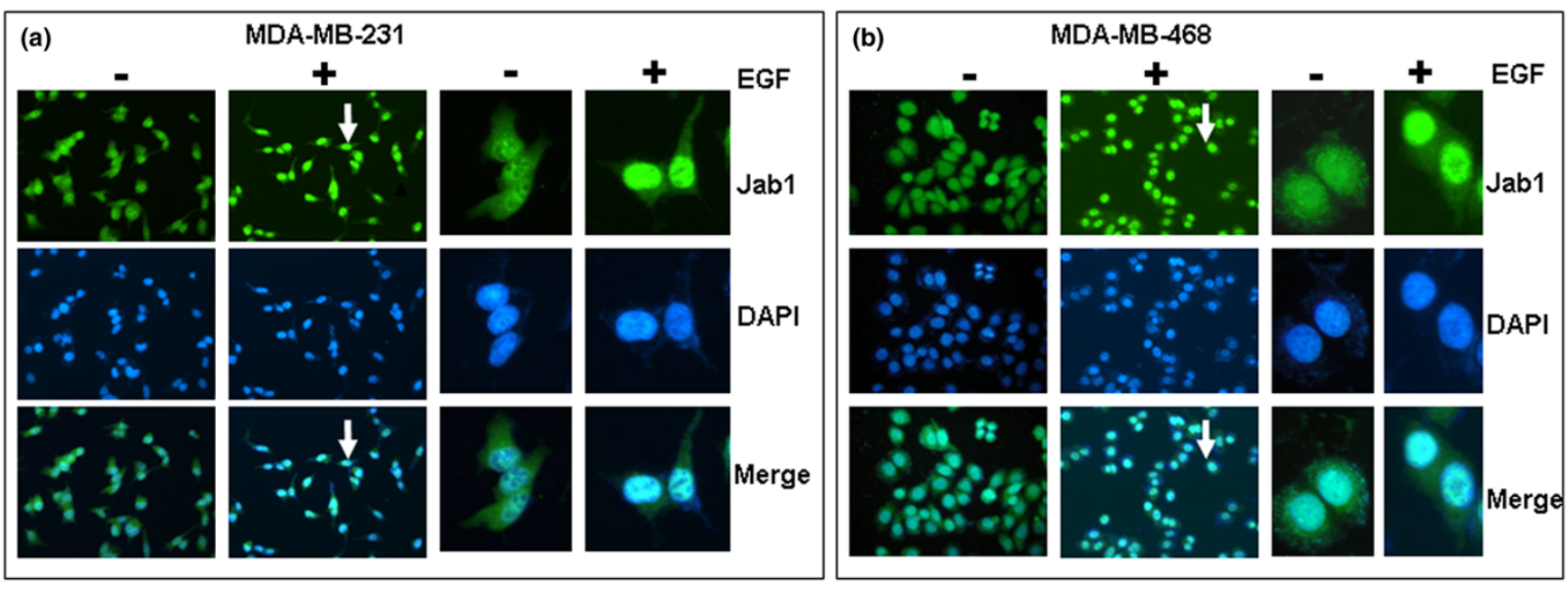

(c)
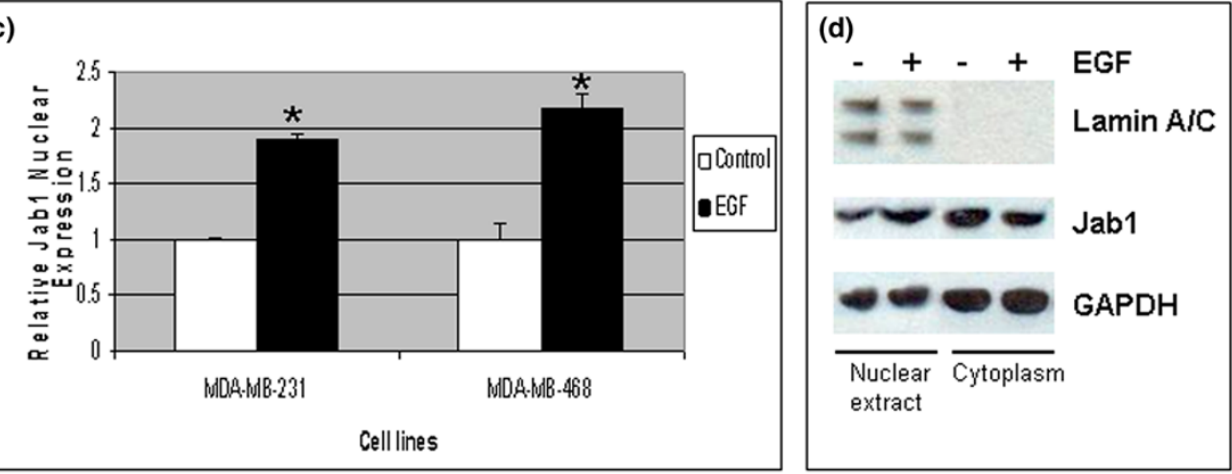

(e)

$\begin{array}{lllll}0 & 1025 & 50 \quad E G F(n g / m l)\end{array}$
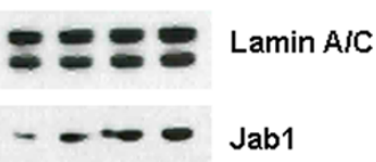

GAPDH

Nuclear extract

Epidermal growth factor (EGF) stimulates increased nuclear localization of Jab1 in MDA-MB-231 and MDA-MB-468 breast cancer cell lines. (a, b) Immunofluorescence assays. (c) Quantitative image analysis of nuclear Jab1 (bars represent mean \pm standard deviation). Statistical analysis was by $t$ test $\left({ }^{\star} P<0.01\right)$. (d) Increased expression of Jab1 in the nucleus relative to cytoplasm, detected by Western blot in MDA-MB-231 nuclear extracts. Lamin A/C was included as a positive control for the nuclear extract, and GAPDH was included as a loading control. (e) Increased Jab1 nuclear expression positively correlated to EGF dose. DAPI, 4'-6-diamidino-2-phenylindole; GAPDH, glyceraldehyde 3-phosphate dehydrogenase; Jab1, cJun activation domain-binding protein-1.

by immunoblots of extracts prepared from EGF-treated MDAMB-231 cells, which showed increased nuclear Jab1 and a corresponding decrease in cytoplasmic Jab1 following EGF treatment (Figure 1d), as well as EGF dose-response experiments that showed increased nuclear Jab1 with increased EGF treatment concentration (Figure 1e). Similar observations were made in MDA-MB-468 cells (data not shown).

\section{Effect of EGF on Jab1 translocation is mediated through the ERK pathway}

The effects of EGF are known to be mediated through the EGFR and by mitogen-activated protein (MAP) kinases [33]. We therefore examined whether the effect of EGF on Jab1 translocation is dependent on selective activation of the MAP kinases: p38, c-jun N-terminal kinase (JNK), and ERK. Experiments in our breast cancer cell lines showed that EGF treatment significantly increased phosphorylation of ERK as measured by immunofluorescence (Figure 2a). Minimal effects of EGF treatment were observed on phosphorylation of p38 and JNK (data not shown). We next looked at the localization of Jab1 and phosphorylated ERK (pERK). Double-immunostaining for these proteins showed that, following EGF treatment, there was an increase in both Jab1 and pERK and that these proteins were colocalized in the nucleus (Figure $2 \mathrm{a}$, bottom row). ERK inhibitor, PD98059, was used in conjunction with EGF stimulation and was shown to effectively block increased nuclear Jab1 expression in MDA-MB-231 cells by both immunofluorescence (Figure 2b) and immunoblotting (Figure 2c). Similar observations were made in MDA-MB-468 cells (data not shown). These results indicate that EGFinduced Jab1 translocation can be mediated through the ERK signaling pathway.

\section{EGFR signaling regulates genes downstream of Jab1}

To investigate whether EGFR signaling has a functional effect on Jab1 activity, we performed immunoblotting and doubleimmunostaining for the Jab1 downstream target, p27. In both MDA-MB-231 and MDA-MB-468 cell lines, Western blot 

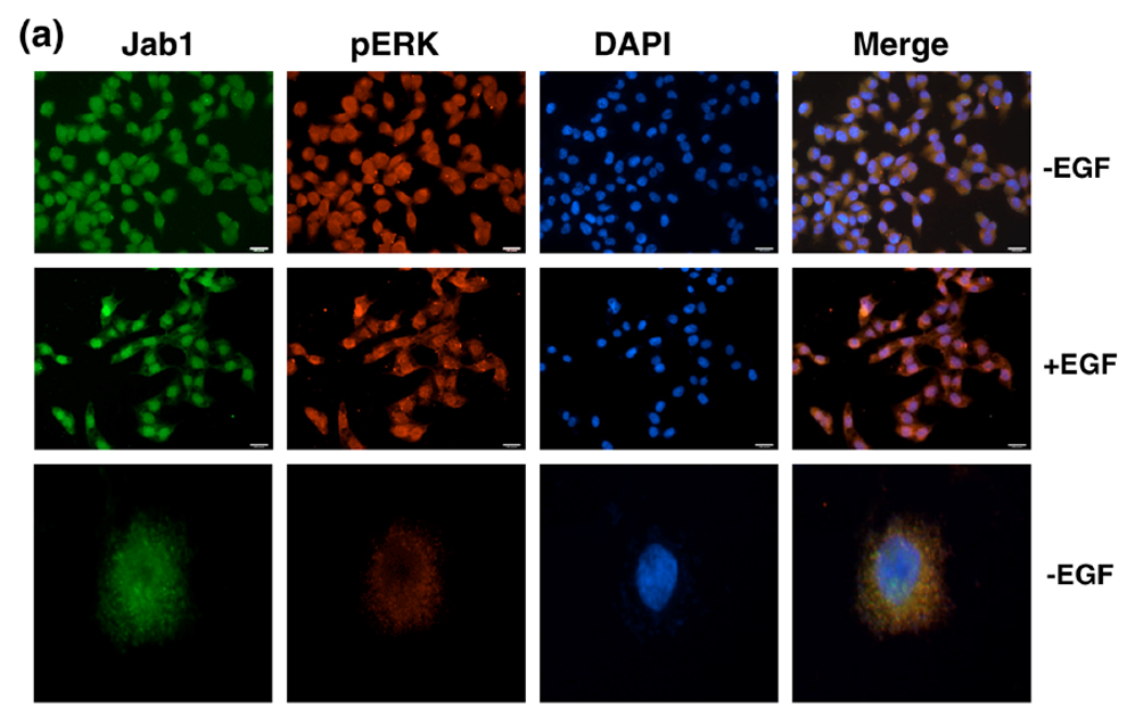

-EGF
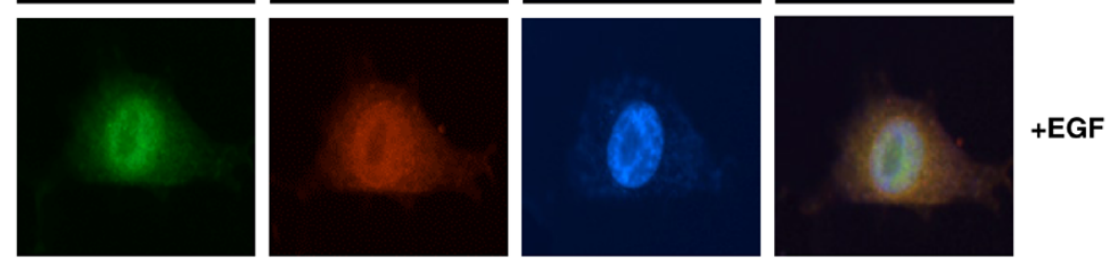

(b)

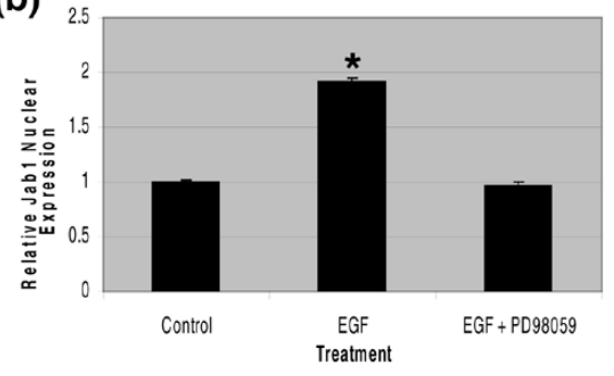

(c)

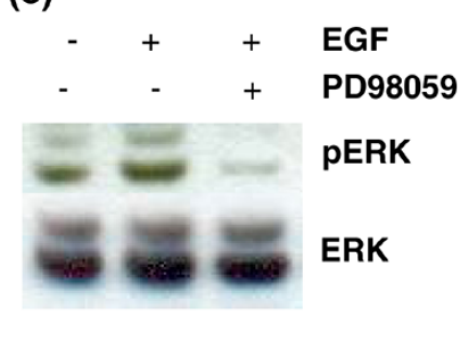

Epidermal growth factor (EGF) stimulation of Jab1 nuclear translocation is dependent on pERK and is associated with pERK in the nucleus in MDAMB-231 cells. (a) Enhanced colocalization of Jab1 and pERK in the nucleus following EGF treatment. (b) Quantitative image analysis of nuclear Jab1 expression in cells treated with EGF and in cells treated with EGF and the ERK inhibitor, PD98059. Bars represent mean \pm standard deviation. Statistical analysis was by $t$ test $\left({ }^{\star} P<0.01\right)$. (c) Increased pERK expression following EGF treatment. The addition of ERK inhibitor, PD98059, eliminated this effect. DAPI, 4'-6-diamidino-2-phenylindole; ERK, extracellular signal-regulated kinase; Jab1, c-Jun activation domain-binding protein-1; pERK, phosphorylated extracellular signal-regulated kinase.

assay showed that EGF treatment and phosphorylation of EGFR resulted in a significant decrease in p27 expression (Figure 3a). Additional observed changes following EGF treatment included increased pAKT (Figure 3a). The inverse correlation between nuclear Jab1 and p27 expression was also observed in double-immunostaining for these proteins (Figure 3b). To confirm that Jab1 was necessary for the effect of EGF on p27, we performed Jab1 knockdown using an siRNA approach in MDA-MB-231 cells in conjunction with EGF treatment. In addition to re-confirming that cells treated with EGF have reduced p27 $(P<0.05)$, we found that Jab1 knockdown restored p27 to EGF-untreated levels compared with cells treated with EGF and control siRNA $(P<0.0001)$ (Figure 4a,b). In cells treated with Jab1 siRNA, EGF had no effect on p27 levels $(P=0.68)$. Taken together, these results indicate not only that EGFR signaling affects Jab1 translocation but that it may regulate targets downstream of Jab1 and that the effect of EGF on p27 levels is mediated by Jab1.

\section{Jab1 expression correlates with EGFR in breast tumors}

To further explore the relationship between EGFR and Jab1 expression in vivo, we examined the expression of these genes in a series of 424 invasive breast tumors using TMAs. The characteristics of the cohort are outlined in Table 1. The relationship between nuclear expression of Jab1 and the level of EGFR was assessed, together with the level of S100A7, 


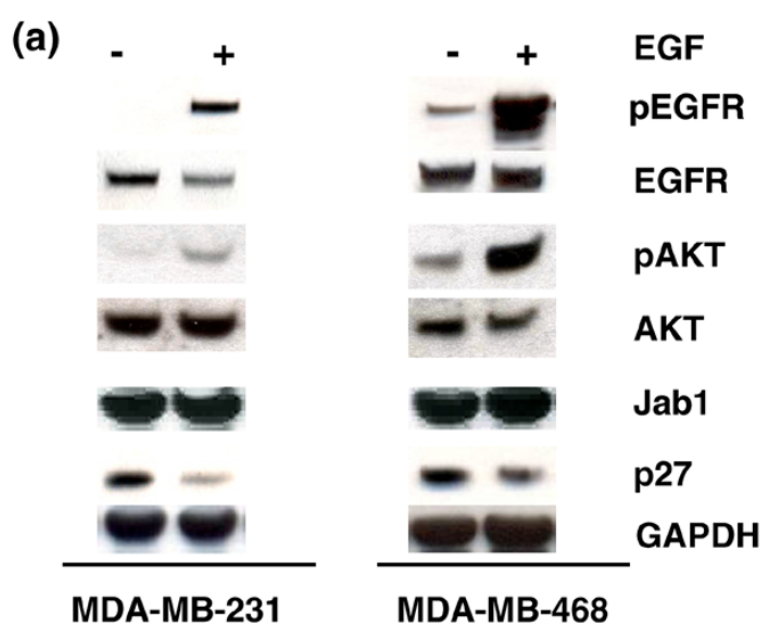

(b)
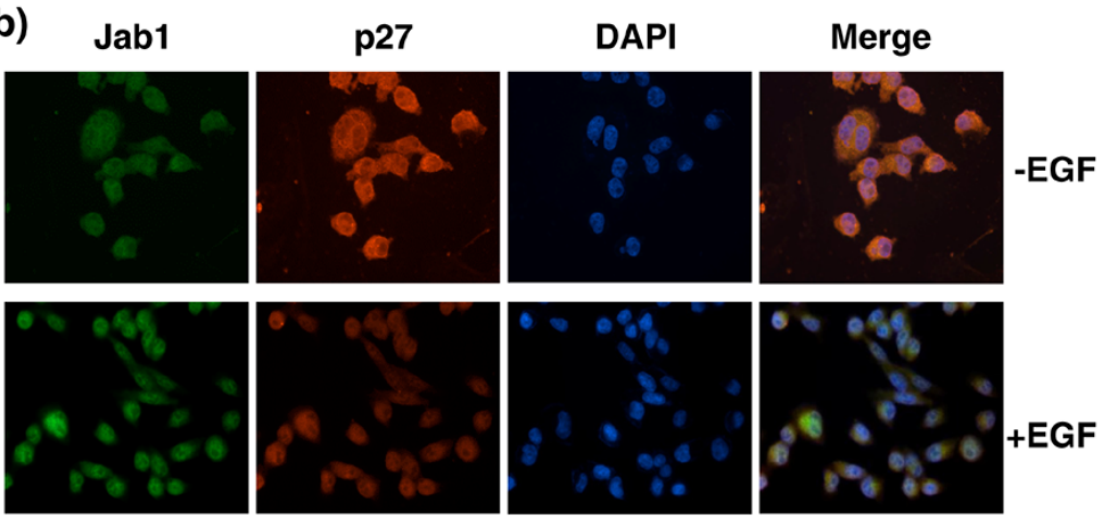

Epidermal growth factor (EGF) influences activity of Jab1 downstream genes. (a) Western blot analysis results show that upregulation of pEGFR is correlated with downregulation of p27 in both MDA-MB-231 and MDA-MB-468 cells following EGF treatment. Treatment with EGF was also correlated to an observed increase in pAKT. GAPDH was included as a loading control. (b) Immunofluorescence analysis confirmed that nuclear translocation of Jab1 was associated with downregulation of its downstream target, p27, following EGF treatment. DAPI, 4'-6-diamidino-2-phenylindole; EGFR, epidermal growth factor receptor; GAPDH, glyceraldehyde 3-phosphate dehydrogenase; Jab1, c-Jun activation domain-binding protein-1; pEGFR, phosphorylated epidermal growth factor receptor.

because of the previously established strong relationship between S100A7 expression and Jab1. In analysis of the entire tumor cohort, high levels of Jab1, EGFR, and S100A7 were seen in 154/424 (36\%), 42/424 (10\%), 144/424 (34\%) cases, respectively (Figure 5). Jab1 was not associated with prognostic factors or biomarkers, including grade, axillary nodal status, tumor size, ER, PR, EGFR, or S100A7, or with overall patient survival when examined in the entire cohort. In subgroup analysis of the $\mathrm{ER} \alpha^{+}$subgroup, no significant associations were observed. However, in subgroup analysis of the ER $\alpha$ - subgroup $(n=154)$, Jab1 levels were associated with axillary node-positive status $(P=0.019, t$ test $)$ and higher levels of Jab1 nuclear expression were associated with both EGFR ( $P=0.019, t$ test) and S100A7 ( $P=0.036, t$ test $)$ (Table 2). Notably, higher Jab1 levels were more strongly associated with combined $\mathrm{EGFR}^{+} / \mathrm{S} 100 \mathrm{~A} 7^{+}$versus EGFR-/ S100A7- status within this subgroup $(P=0.004, t$ test).
Outcome analysis of the ER $\alpha$ - subgroup showed no significant association between survival and Jab1+, EGFR+, or S100A7+ status when each marker was analyzed independently. Comparison of the subset of $E R \alpha^{-}$tumors that were positive for all three markers, EGFR/S100A7/Jab1, showed that this phenotype was associated with worse outcome compared with EGFR/S100A7/Jab1 1 tumors ( $=10$ versus $13 ; P=$ 0.07).

\section{Discussion}

$E R \alpha$, and in particular the 'triple-negative' subset of breast cancer lacking detectable ER $\alpha, \mathrm{PR}$, and Her2, has emerged as a challenge for systemic therapy now that successful targeted therapies have become available for the treatment of other phenotypic subgroups. Nevertheless, one prominent feature of the ER $\alpha$ - subgroup is expression of the EGFR $[34,35]$, raising the possibility that this receptor may offer a tar- 
Figure 4
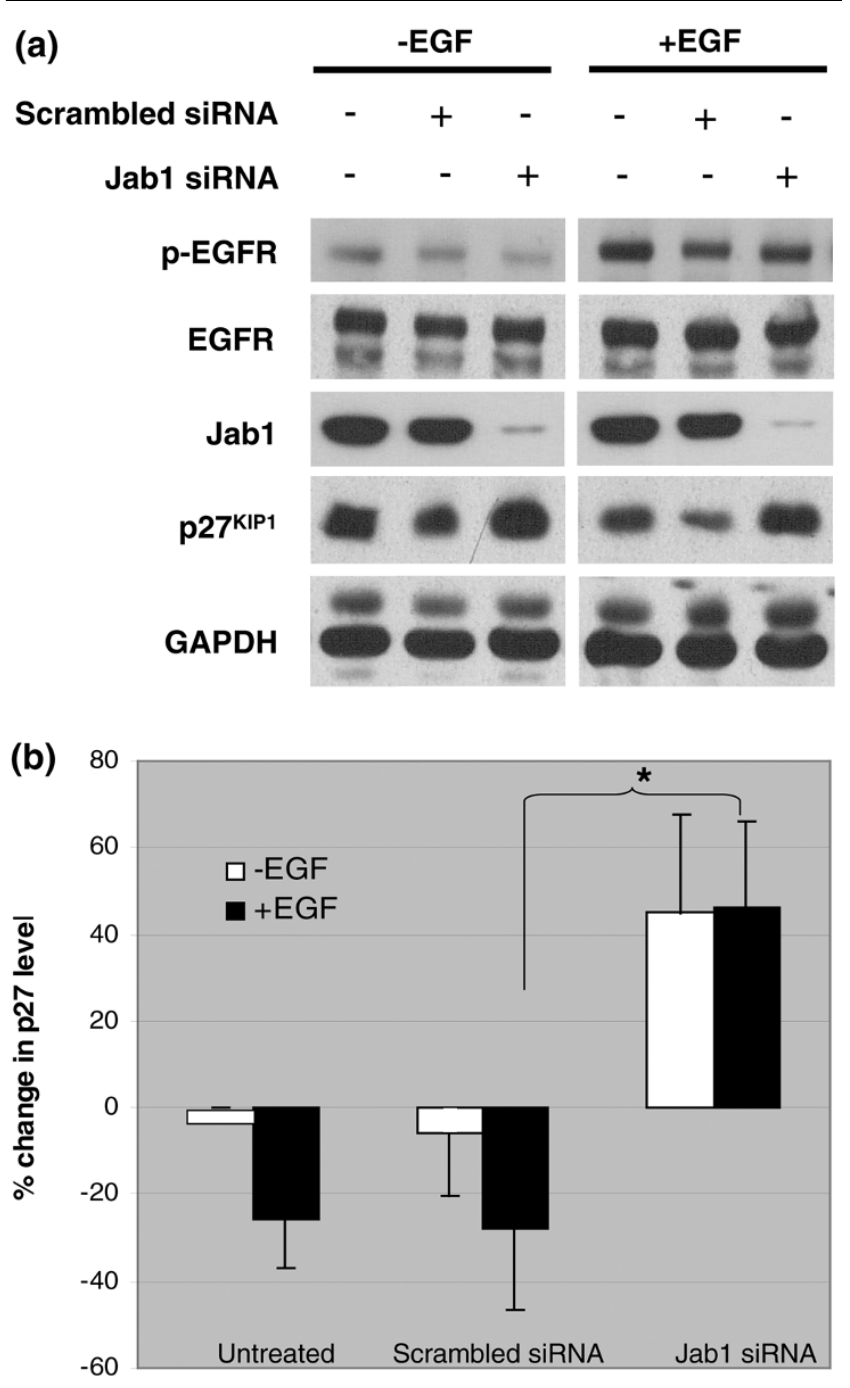

siRNA treatment

Effect of Jab1 short interfering RNA (siRNA) knockdown on p27 levels with and without epidermal growth factor (EGF) treatment in MDA-MB231 cells. (a) Western blot analysis of cell lysates collected following the indicated treatments. Relative p27 band intensities were calculated by densitometry and normalized to the loading control (GAPDH). (b) The percentage change in $\mathrm{p} 27$ expression for EGF-treated cells relative to untreated controls. Data shown are representative of several independent experiments, demonstrating that knockdown of Jab1 abrogates EGF-induced downregulation of $\mathrm{p} 27$. Bars represent mean \pm standard deviation. Statistical analysis was by $t$ test $\left({ }^{\star} P<0.0001\right)$. All EGF treatments were at $50 \mathrm{ng} / \mathrm{mL}$ for 4 hours. EGFR, epidermal growth factor receptor; GAPDH, glyceraldehyde 3-phosphate dehydrogenase; Jab1, c-Jun activation domain-binding protein-1; pEGFR, phosphorylated epidermal growth factor receptor.

get for treatment of this subgroup. However, anti-EGFR therapies, alone or in combination with chemotherapy, have benefited only a small cohort of patients in the face of both de novo and acquired resistance to these therapies [36]. To circumvent this resistance, it will be important to understand more of the signaling pathways downstream of EGFR in ER $\alpha$ tumors [37]. Recent findings suggest that the Jab1 protein may be the central mediator in several of the biological circuits that promote tumor progression in breast cancer cells [37]. We have therefore set out to explore whether Jab1 is also involved in EGFR signaling. We have shown that EGFR activation in $E R \alpha^{-}$breast cell lines is associated with Jab1 nuclear localization and that these changes relate to activation of both AKT and ERK pathways and modulation of Jab1 downstream genes. Furthermore, higher Jab1 nuclear expression was associated with $\mathrm{EGFR}^{+}$status in a cohort of $\mathrm{ER} \alpha$ - breast tumors, and this relationship was most significant in tumors that expressed both EGFR and S100A7 markers.

Jab1 is a multifunctional protein that has been shown to interact with several components of cell signaling pathways within in vitro yeast systems and human cell lines. These interactions usually are associated with translocation of Jab1 from the cytoplasm to the nucleus and result in either enhanced activity of transcription factors, including c-Jun [26,38], AP-1 [26,38], HIF-1 $\alpha$ [39], steroid receptors, and cofactors [40], or the promotion of degradation of interacting proteins, including p27 [27,32], Smad4 [28], MIF1 [41], and p53 [42]. Although the physiological relevance of some of these interactions is mostly unknown (specifically, within the context of breast epithelial cells [43]), they are evidently complex. For example, in documenting that EGF can affect Jab1 localization in breast cells, we have confirmed previous findings that EGF affects a representative Jab1 downstream gene, p27, and that these effects correlate with alterations of PI3K (phosphatidylinositol-3kinase)/AKT [44,45]. However, we also show here that changes in the ERK pathway may contribute to the effects of Jab1 in some breast cell lines. Interestingly, others recently have shown that Her2 (EGFR2) signaling can regulate Jab1 through the AKT/ $\beta$-catenin pathway [23] and, in a subsequent study, that Her2 modulates p27 through Jab1 [23]. In contrast to our data and other interaction effects, these studies concluded that Her2-mediated Jab1 regulation occurs at the transcriptional level. Others have shown Her2 activation to be associated with relocalization to the cytoplasm rather than nuclear accumulation of Jab1 [46] and that activation of the Her2-ras-MAP kinase pathway can alter Jab1 and stimulate downregulation of p27 [47]. One potential explanation for these apparent incongruities relates to the different cell lines used in these studies [23].

Jab1 recently has been identified as a master regulator of a spectrum of genes (the 'wound response signature') that may promote tumor progression in breast cancer [24,25]. Jab1 also acts as an essential modulator of c-myc transcriptional activity, regulating c-myc protein ubiquitination and stability. Thus, Jab1 and c-myc together influence the expression of a subset of cmyc-regulated genes that comprise the 'wound response'. Jab1 and c-myc expression and upregulation of the wound response signature do not appear to be limited to specific phenotypic 


\section{Figure 5}

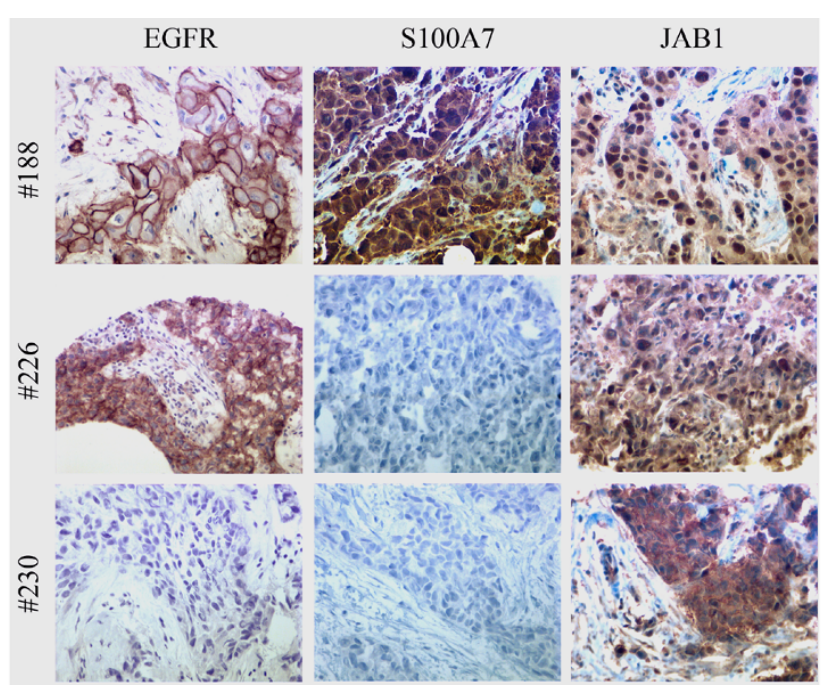

Jab1 nuclear expression correlates with increased EGFR and S100A7 in breast tumors. EGFR, S100A7, and Jab1 were detected by immunohistochemistry in breast tumors represented within a tissue microarray. Representative staining is shown for all three markers and in three separate tumors. Tumor \#188 (top row) shows high nuclear Jab1 expression associated with high EGFR and S100A7 expression. Tumor \#226 (middle row) shows intermediate nuclear and cytoplasmic Jab1 expression associated with moderate EGFR and absence of S100A7 expression. Tumor \#230 (bottom row) shows low nuclear but high cytoplasmic Jab1 expression associated with the absence of EGFR or S100A7 expression. EGFR, epidermal growth factor receptor; Jab1, c-Jun activation domain-binding protein-1.

\section{Table 1}

\section{Clinicopathological features of the tumor cohort}

\begin{tabular}{|c|c|c|c|}
\hline Parameter & & Number & Percentage \\
\hline \multicolumn{4}{|l|}{ Grade $^{a}$} \\
\hline & Low & 69 & $16 \%$ \\
\hline & Intermediate & 237 & $56 \%$ \\
\hline & High & 90 & $21 \%$ \\
\hline & Unknown & 28 & $7 \%$ \\
\hline \multicolumn{4}{|l|}{ Size } \\
\hline & $\leq 2 \mathrm{~cm}$ & 115 & $27 \%$ \\
\hline & $>2 \mathrm{~cm}$ & 304 & $71 \%$ \\
\hline & Unknown & 5 & $2 \%$ \\
\hline \multicolumn{4}{|c|}{ Nodal status } \\
\hline & Negative & 163 & $38 \%$ \\
\hline & Positive & 249 & $59 \%$ \\
\hline & Unknown & 12 & $3 \%$ \\
\hline \multicolumn{4}{|c|}{ Estrogen receptorb } \\
\hline & Negative & 154 & $36 \%$ \\
\hline & Positive & 270 & $64 \%$ \\
\hline \multicolumn{4}{|c|}{ Progesterone receptorc } \\
\hline & Negative & 189 & $45 \%$ \\
\hline & Positive & 235 & $55 \%$ \\
\hline
\end{tabular}

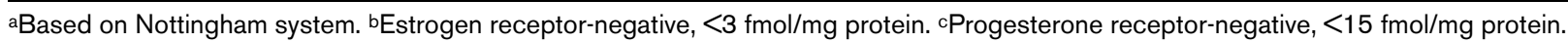


Table 2

Correlation between Jab1 expression and clinicopathological features of the estrogen receptor-alpha-negative ${ }^{\text {subset }}$

\begin{tabular}{|c|c|c|c|c|c|}
\hline Parameter & & \multicolumn{4}{|c|}{ Jab1 } \\
\hline \multicolumn{6}{|l|}{ Grade $^{b}$} \\
\hline & Low & 12 & 91 & (79) & NS \\
\hline & Intermediate & 70 & 61 & (51) & \\
\hline & High & 72 & 49 & (43) & \\
\hline \multicolumn{6}{|l|}{ Size } \\
\hline & $\leq 2 \mathrm{~cm}$ & 32 & 71 & (63) & NS \\
\hline & $>2 \mathrm{~cm}$ & 118 & 55 & (50) & \\
\hline \multicolumn{6}{|c|}{ Nodal status } \\
\hline & Negative & 55 & 43 & $(46)$ & 0.019 \\
\hline & Positive & 87 & 64 & (55) & \\
\hline \multicolumn{6}{|c|}{ Progesterone receptor ${ }^{c}$} \\
\hline & Negative & 120 & 59 & $(51)$ & NS \\
\hline & Positive & 34 & 53 & $(57)$ & \\
\hline \multicolumn{6}{|l|}{ EGFR } \\
\hline & Negative & 123 & 53 & (50) & 0.019 \\
\hline & Positive & 31 & 78 & $(57)$ & \\
\hline \multicolumn{6}{|l|}{ S100A7 } \\
\hline & Negative & 59 & 48 & $(47)$ & 0.036 \\
\hline & Positive & 95 & 64 & (55) & \\
\hline
\end{tabular}

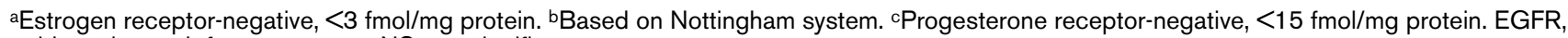
epidermal growth factor receptor; NS, not significant.

subgroups of breast tumors [48]. However, deregulation of cmyc is known to occur in ER $\alpha$-breast cell lines and to be associated with PR- breast cancer and resistance to endocrine therapy $[49,50]$. We have previously identified Jab1 as a mediator of several intracellular and biological effects of S100A7, which itself may promote breast tumor progression [21,22]. Pathways downstream of S100A7 are also of interest because of this gene's strong association with the ER $\alpha$ - phenotype in $\mathrm{DCIS}$ and, when expression persists, in invasive breast cancer $[7,8,18,19]$.

These observations raise the question of whether Jab1 is a common factor in mediating cell signaling pathways that are important in ER $\alpha$-breast cancer. Our data presented here suggest that Jab1 may be regulated by the EGFR and S100A7 pathways in ER $\alpha$ - breast cells. Notably, we [6] and (very recently) others [51] have shown that there may be crosstalk between S100A7 and EGFR and that S100A7 can regulate EGFR signaling. Jab1 expression in breast cancer has been explored previously by us [52] and others [23,29,53]. High nuclear Jab1 was associated with reduced p27 expression in all of these studies, in both DCIS [52] and invasive disease
[29,53]. But no consistent association with any prognostic features, including ER $\alpha$ status, has emerged. However, there is some indication that increased Jab1 might be related to poor outcome [29]. Nevertheless, these studies were based on small [23] and/or highly selected case series (in terms of stage [52] and nodal status [29,53]). The present study has now extended these findings by assessing nuclear Jab1 expression in relation to prognostic features and markers in a large cohort of invasive breast tumors representative of the case distribution in a large tumor bank. We have confirmed that Jab1 is not strongly correlated with any prognostic features examined, except in subset analysis in which there was a positive association with nodal metastasis in the ER $\alpha$ - subset. Despite the observation of a possible association between Jab1 and worse outcome in the ER $\alpha^{-}$subset, this was not statistically significant, and the same was true for EGFR and S100A7. This difference from previous findings $[6,29,54]$ may relate to the use of a TMA for the present study. While this format is optimal for examining coexpression of biomarkers within small defined tumor regions, it may not be optimal for outcome analyses of genes that are heterogeneously expressed within tumors. However, the aggregate results from 
this and other studies support the conclusion that nuclear Jab1 is only weakly related, if at all, to standard prognostic features and outcome as an independent factor.

This lack of clear association with complex phenotypic traits represented by prognostic factors such as tumor grade or with patient outcome is intriguing given the range of potentially important signaling pathways and proteins that Jab1 influences. On the other hand, it is perhaps not surprising given that these multiple factors may influence the equilibrium between nuclear and cytoplasmic Jab1 and its activity. It has also been shown that p53 and c-Jun can compete for Jab1 [47]. These and other interacting proteins might influence its collaborative role with c-myc as a regulator of the wound response. Jab1 can also exist in several different protein complexes within both cellular compartments in breast cells, further complicating analysis and deductions based only on protein localization [25]. It will be interesting to examine Jab1 in relation to c-myc and Jab1 protein complex status in future outcome analyses.

\section{Conclusion}

Jab1 lies at the intersection of several signaling pathways that are believed to be important in breast cancer cells and may be a decisive influence on the outcome of specific pathway alterations and their cumulative effects on progression. Our results implicating Jab1 in the EGFR pathway, in addition to its role in the S100A7 pathway, suggest that Jab1 may be particularly important in the ER $\alpha$ - breast cancer cell and provide insight into the application of new therapeutic strategies (for example, proteasome inhibitors) directed to this important and difficultto-treat subset of breast cancer.

\section{Competing interests}

The authors declare that they have no competing interests.

\section{Authors' contributions}

PHW supervised all aspects of this study and contributed to the manuscript preparation. JW participated in the overall experimental design and data interpretation. ROB participated in the manuscript preparation and data interpretation. NRW performed all of the knockdown experiments and participated in the data interpretation. MO performed most of the cell culture and immunofluorescence assays. JEC performed most of the Western blot analyses. All authors read and approved the final manuscript.

\section{Acknowledgements}

$\mathrm{PHW}$ is supported by an operating grant from the Canadian Institutes of Health Research (CIHR) (grant number MOP-64349). JW is supported by a Michael Smith Foundation for Health Research Trainee Fellowship and by a Susan Komen for the Cure Postdoctoral Fellowship grant. This study was also supported by the BC Cancer Agency's Tumor Tissue Repository and the Manitoba Breast Tumor Bank, funded by a grant from the ClHR (grant number PRG80155), and supported by CancerCare Manitoba.

\section{References}

1. Abba MC, Hu Y, Sun H, Drake JA, Gaddis S, Baggerly K, Sahin A, Aldaz CM: Gene expression signature of estrogen receptor alpha status in breast cancer. BMC Genomics 2005, 6:37.

2. Gruvberger-Saal SK, Eden P, Ringner M, Baldetorp B, Chebil G, Borg A, Ferno M, Peterson C, Meltzer PS: Predicting continuous values of prognostic markers in breast cancer from microarray gene expression profiles. Mol Cancer Ther 2004, 3:161-168.

3. Biswas DK, Iglehart JD: Linkage between EGFR family receptors and nuclear factor kappaB (NF-kappaB) signaling in breast cancer. J Cell Physiol 2006, 209:645-652.

4. Biswas DK, Shi Q, Baily S, Strickland I, Ghosh S, Pardee AB, Iglehart JD: NF-kappa B activation in human breast cancer specimens and its role in cell proliferation and apoptosis. Proc Natl Acad Sci USA 2004, 101:10137-10142.

5. Biswas DK, Dai SC, Cruz A, Weiser B, Graner E, Pardee AB: The nuclear factor kappa B (NF-kappa B): a potential therapeutic target for estrogen receptor negative breast cancers. Proc Natl Acad Sci USA 2001, 98:10386-10391.

6. Emberley ED, Niu Y, Njue C, Kliewer EV, Murphy LC, Watson PH: Psoriasin (S100A7) expression is associated with poor outcome in estrogen receptor-negative invasive breast cancer. Clin Cancer Res 2003, 9:2627-2631.

7. Emberley ED, Alowami S, Snell L, Murphy LC, Watson PH: S100A7 (psoriasin) expression is associated with aggressive features and alteration of Jab1 in ductal carcinoma in situ of the breast. Breast Cancer Res 2004, 6:R308-315.

8. Al-Haddad S, Zhang Z, Leygue E, Snell L, Huang A, Niu Y, HillerHitchcock T, Hole K, Murphy LC, Watson PH: Psoriasin (S100A7) expression and invasive breast cancer. Am J Pathol 1999, 155:2057-2066.

9. Krop I, März A, Carlsson H, Li X, Bloushtain-Qimron N, Hu M, Gelman R, Sabel MS, Schnitt S, Ramaswamy S, Kleer CG, Enerbäck C, Polyak K: A putative role for psoriasin in breast tumor progression. Cancer Res 2005, 65:11326-11334.

10. Bundred NJ, Chan K, Anderson NG: Studies of epidermal growth factor receptor inhibition in breast cancer. Endocr Relat Cancer 2001, 8:183-189.

11. Klijn JG, Berns PM, Schmitz PI, Foekens JA: The clinical significance of epidermal growth factor receptor (EGF-R) in human breast cancer: a review on $\mathbf{5 2 3 2}$ patients. Endocr Rev 1992, 13:3-17.

12. Fox SB, Smith K, Hollyer J, Greenall M, Hastrich D, Harris AL: The epidermal growth factor receptor as a prognostic marker: results of $\mathbf{3 7 0}$ patients and review of $\mathbf{3 0 0 9}$ patients. Breast Cancer Res Treat 1994, 29:41-49.

13. Harris AL, Nicholson S, Sainsbury R, Wright C, Farndon J: Epidermal growth factor receptor and other oncogenes as prognostic markers. J Natl Cancer Inst Monogr 1992:181-187.

14. Rampaul RS, Pinder SE, Nicholson RI, Gullick WJ, Robertson JF, Ellis IO: Clinical value of epidermal growth factor receptor expression in primary breast cancer. Adv Anat Pathol 2005, 12:271-273.

15. Zeillinger R, Kury F, Speiser P, Sliutz G, Czerwenka K, Kubista E: EGF-R and steroid receptors in breast cancer: a comparison with tumor grading, tumor size, lymph node involvement, and age. Clin Biochem 1993, 26:221-227.

16. Ridinger K, llg EC, Niggli FK, Heizmann CW, Schafer BW: Clustered organization of $\mathbf{S} 100$ genes in human and mouse. Biochim Biophys Acta 1998, 1448:254-263.

17. Borglum AD, Flint T, Madsen $P$, Celis JE, Kruse TA: Refined mapping of the psoriasin gene S100A7 to chromosome 1cen-q21. Hum Genet 1995, 96:592-596.

18. Leygue E, Snell L, Hiller T, Dotzlaw H, Hole K, Murphy LC, Watson $\mathrm{PH}$ : Differential expression of psoriasin messenger RNA between in situ and invasive human breast carcinoma. Cancer Res 1996, 56:4606-4609.

19. Enerbäck C, Porter DA, Seth P, Sgroi D, Gaudet J, Weremowicz S, Morton CC, Schnitt S, Pitts RL, Stampl J, Barnhart K, Polyak K: Psoriasin expression in mammary epithelial cells in vitro and in vivo. Cancer Res 2002, 62:43-47.

20. Porter DA, Krop IE, Nasser S, Sgroi D, Kaelin CM, Marks JR, Riggins G, Polyak K: A SAGE (serial analysis of gene expression) view of breast tumor progression. Cancer Res 2001, 61:5697-5702. 
21. Emberley ED, Niu Y, Leygue E, Tomes L, Gietz RD, Murphy LC, Watson $\mathrm{PH}$ : Psoriasin interacts with Jab1 and influences breast cancer progression. Cancer Res 2003, 63:1954-1961.

22. Emberley ED, Niu Y, Curtis L, Troup S, Mandal SK, Myers JN, Gibson SB, Murphy LC, Watson PH: The S100A7-c-Jun activation domain binding protein 1 pathway enhances prosurvival pathways in breast cancer. Cancer Res 2005, 65:5696-5702.

23. Hsu MC, Chai CY, Hou MF, Chang HC, Chen WT, Hung WC: Jab1 is overexpressed in human breast cancer and is a downstream target for HER-2/neu. Mod Patho/ 2008, 21:609-616.

24. Adler AS, Lin M, Horlings $H$, Nuyten DS, Vijver MJ van de, Chang $\mathrm{HY}$ : Genetic regulators of large-scale transcriptional signatures in cancer. Nat Genet 2006, 38:421-430.

25. Adler AS, Littlepage LE, Lin M, Kawahara TL, Wong DJ, Werb Z, Chang HY: CSN5 isopeptidase activity links COP9 signalosome activation to breast cancer progression. Cancer Res 2008, 68:506-515.

26. Claret FX, Hibi M, Dhut S, Toda T, Karin M: A new group of conserved coactivators that increase the specificity of AP-1 transcription factors. Nature 1996, 383:453-457.

27. Tomoda K, Kubota Y, Arata Y, Mori S, Maeda M, Tanaka T, Yoshida $\mathrm{M}$, Yoneda-Kato N, Kato JY: The cytoplasmic shuttling and subsequent degradation of p27Kip1 mediated by Jab1/CSN5 and the COP9 signalosome complex. J Biol Chem 2002, 277:2302-2310.

28. Wan M, Cao X, Wu Y, Bai S, Wu L, Shi X, Wang N, Cao X: Jab1 antagonizes TGF-beta signaling by inducing Smad4 degradation. EMBO Rep 2002, 3:171-176.

29. Kouvaraki MA, Rassidakis GZ, Tian L, Kumar R, Kittas C, Claret FX: Jun activation domain-binding protein 1 expression in breast cancer inversely correlates with the cell cycle inhibitor p27(Kip1). Cancer Res 2003, 63:2977-2981.

30. Wolff AC, Hammond ME, Schwartz JN, Hagerty KL, Allred DC, Cote RJ, Dowsett M, Fitzgibbons PL, Hanna WM, Langer A, McShane LM, Paik S, Pegram MD, Perez EA, Press MF, Rhodes A, Sturgeon C, Taube SE, Tubbs R, Vance GH, Vijver M van de, Wheeler TM, Hayes DF, American Society of Clinical Oncology; College of American Pathologists: American Society of Clinical Oncology/College of American Pathologists guideline recommendations for human epidermal growth factor receptor 2 testing in breast cancer. J Clin Oncol 2007, 25:118-145.

31. Bianchi E, Denti S, Granata A, Bossi G, Geginat J, Villa A, Rogge L, Pardi R: Integrin LFA-1 interacts with the transcriptional coactivator JAB1 to modulate AP-1 activity. Nature 2000, 404:617-621.

32. Tomoda K, Kubota Y, Kato J: Degradation of the cyclin-dependent-kinase inhibitor p27Kip1 is instigated by Jab1. Nature 1999, 398:160-165.

33. Song RX, Zhang Z, Chen Y, Bao Y, Santen RJ: Estrogen signaling via a linear pathway involving insulin-like growth factor I receptor, matrix metalloproteinases, and epidermal growth factor receptor to activate mitogen-activated protein kinase in MCF-7 breast cancer cells. Endocrinology 2007, 148:4091-4101.

34. Allred DC, Clark GM, Molina R, Tandon AK, Schnitt SJ, Gilchrist KW, Osborne CK, Tormey DC, McGuire WL: Overexpression of HER-2/neu and its relationship with other prognostic factors change during the progression of in situ to invasive breast cancer. Hum Pathol 1992, 23:974-979.

35. Zeillinger R, Kury F, Czerwenka K, Kubista E, Sliutz G, Knogler W, Huber J, Zielinski C, Reiner G, Jakesz R, et al:: HER-2 amplification, steroid receptors and epidermal growth factor receptor in primary breast cancer. Oncogene 1989, 4:109-114.

36. Hutcheson IR, Knowlden JM, Jones HE, Burmi RS, McClelland RA, Barrow D, Gee JM, Nicholson RI: Inductive mechanisms limiting response to anti-epidermal growth factor receptor therapy. Endocr Relat Cancer 2006, 13(Suppl 1):S89-97.

37. Hutcheson IR, Knowlden JM, Madden TA, Barrow D, Gee JM, Wakeling AE, Nicholson RI: Oestrogen receptor-mediated modulation of the EGFR/MAPK pathway in tamoxifen-resistant MCF-7 cells. Breast Cancer Res Treat 2003, 81:81-93.

38. Naumann M, Bech-Otschir D, Huang X, Ferrell K, Dubiel W: COP9 signalosome-directed c-Jun activation/stabilization is independent of JNK. J Biol Chem 1999, 274:35297-35300.

39. Bae MK, Ahn MY, Jeong JW, Bae MH, Lee YM, Bae SK, Park JW, Kim KR, Kim KW: Jab1 interacts directly with HIF-1alpha and regulates its stability. J Biol Chem 2002, 277:9-12.
40. Chauchereau A, Georgiakaki M, Perrin-Wolff M, Milgrom E, Loosfelt $\mathrm{H}$ : JAB1 interacts with both the progesterone receptor and SRC-1. J Biol Chem 2000, 275:8540-8548.

41. Kleemann R, Hausser A, Geiger G, Mischke R, Burger-Kentischer A, Flieger O, Johannes FJ, Roger T, Calandra T, Kapurniotu A, Grell $\mathrm{M}$, Finkelmeier D, Brunner $\mathrm{H}$, Bernhagen J: Intracellular action of the cytokine MIF to modulate AP-1 activity and the cell cycle through Jab1. Nature 2000, 408:211-216.

42. Bech-Otschir D, Kraft R, Huang X, Henklein P, Kapelari B, Pollmann C, Dubiel W: COP9 signalosome-specific phosphorylation targets p53 to degradation by the ubiquitin system. EMBO J 2001, 20:1630-1639.

43. Nordgard O, Dahle O, Andersen TO, Gabrielsen OS: JAB1/CSN5 interacts with the GAL4 DNA binding domain: a note of caution about two-hybrid interactions. Biochimie 2001, 83:969-971.

44. Liang J, Zubovitz J, Petrocelli T, Kotchetkov R, Connor MK, Han K, Lee JH, Ciarallo S, Catzavelos C, Beniston R, Franssen E, Slingerland JM: PKB/Akt phosphorylates p27, impairs nuclear import of p27 and opposes p27-mediated G1 arrest. Nat Med 2002, 8:1153-1160.

45. Motti ML, De Marco C, Califano D, Fusco A, Viglietto G: Aktdependent T198 phosphorylation of cyclin-dependent kinase inhibitor p27kip1 in breast cancer. Cell Cycle 2004, 3:1074-1080.

46. Le XF, Pruefer F, Bast RC Jr: HER2-targeting antibodies modulate the cyclin-dependent kinase inhibitor p27Kip1 via multiple signaling pathways. Cell Cycle 2005, 4:87-95.

47. Pollmann C, Huang X, Mall J, Bech-Otschir D, Naumann M, Dubiel $\mathrm{W}$ : The constitutive photomorphogenesis 9 signalosome directs vascular endothelial growth factor production in tumor cells. Cancer Res 2001, 61:8416-8421.

48. Nuyten DS, Kreike B, Hart AA, Chi JT, Sneddon JB, Wessels LF Peterse HJ, Bartelink H, Brown PO, Chang HY, Vijver MJ van de: Predicting a local recurrence after breast-conserving therapy by gene expression profiling. Breast Cancer Res 2006, 8:R62.

49. Shiu RP, Watson PH, Dubik D: c-myc oncogene expression in estrogen-dependent and -independent breast cancer. Clin Chem 1993, 39:353-355.

50. Deming SL, Nass SJ, Dickson RB, Trock BJ: C-myc amplification in breast cancer: a meta-analysis of its occurrence and prognostic relevance. $\mathrm{Br} J$ Cancer 2000, 83:1688-1695.

51. Paruchuri V, Prasad A, McHugh K, Bhat HK, Polyak K, Ganju RK: S100A7-Downregulation inhibits epidermal growth factorinduced signaling in breast cancer cells and blocks osteoclast formation. PLOS ONE 2008, 3:e1741.

52. Emberley ED, Murphy LC, Watson PH: S100A7 and the progression of breast cancer. Breast Cancer Res 2004, 6:153-159.

53. Esteva FJ, Sahin AA, Rassidakis GZ, Yuan LX, Smith TL, Yang Y, Gilcrease MZ, Cristofanilli M, Nahta R, Pusztai L, Claret FX: Jun activation domain binding protein 1 expression is associated with low p27(Kip1)levels in node-negative breast cancer. Clin Cancer Res 2003, 9:5652-5659.

54. Tsutsui S, Ohno S, Murakami S, Hachitanda Y, Oda S: Prognostic value of epidermal growth factor receptor (EGFR) and its relationship to the estrogen receptor status in 1029 patients with breast cancer. Breast Cancer Res Treat 2002, 71:67-75. 